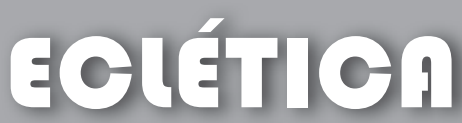 química
}

\section{QUIMIOMETRIA COMO FERRAMENTA ANALITICA PARA DEFINIÇÃO DAS CONDIÇOES DE ENSAIO DA ENZIMA PEROXIDASE DE SOJA}

\author{
Santos, M.C. , Tognolli, J.O. , Oliveira, O.M.M.F..$^{{ }^{*}}$ \\ ${ }^{1}$ UNESP, Universidade Estadual Paulista, Instituto de Química, C.P. 355, 14800-010, Araraquara-SP, Brasil; \\ "autor para correspondência: Fone: +55=16-3301-6672.e-mail: olgamascarenhaso@gmail.com
}

\begin{abstract}
Resumo: Enzimas Peroxidases são heme-proteínas encontradas nos diferentes organismos vivos, especialmente vegetais, apresentam importante papel fisiológico/bioquímico como proteção contra microorganismos invasores. A soja, um dos mais importantes produtos para o agronegócio brasileiro apresenta na casca de suas sementes (subproduto) alta atividade de peroxidase, denominada soybean peroxidase,com potencial de utilização em métodos analíticos clínicos. A proposta do trabalho foi aplicar o planejamento fatorial para otimização das condições extração da enzima, definição das condições ótimas de atividade ( $\mathrm{pH}$ e temperatura), utilizando metodologia de superfície de resposta. Os dados obtidos com clara definição foram: i) extração em pó cetonico, ii) meio reacional: $\mathrm{pH} 3,3$, volume da amostra contendo a enzima $330 \mu \mathrm{L}-340 \mu \mathrm{L}$, peróxido de hidrogênio $4,2 \mathrm{mmol} . \mathrm{L}^{-1} 150 \mu \mathrm{L}$, tempo de reação 20 segundos, temperatura $50^{\circ} \mathrm{C}$, substrato guaiacol $30 \mathrm{mmol} . \mathrm{L}^{-1} 300 \mu \mathrm{L}$, e $0,1 \mathrm{~mol} . \mathrm{L}^{-1}$ de NaCl . O uso da dessa metodologia para definição das condições de extração e estudos cinético-enzimáticos da peroxidase de soja foram eficientes e mais precisos, comparado a metodologia de variações/repetições (tentativa e erro).
\end{abstract}

Palavras-chave: peroxidase de soja; temperatura ótima; pH ótimo; extração; parâmetros cinéticos.

\section{Introdução}

A técnica quimiométrica, que usa regressão por mínimos quadrados parciais (PLS), área multidisciplinar do conhecimento, envolve a matemática e a estatística na análise de dados obtidos em processos químicos, de natureza multivariada. Tal técnica visa o delineamento e a análise de experimentos, estudando e identificando as variáveis, denominadas variáveis latentes, analisando com as relações existentes entre os dados físico-quimicos e o sistema em estudo, através de um planejamento fatorial e de superfície de resposta [1].

O planejamento experimental tem como objetivo reduzir o número de experimentos a serem realizados, sem prejuízo da confiabilidade dos resultados [1]. Maciel et all em 2007, concluíram que o planejamento experimental é aplicável ao estudo da peroxidase de folhas de Copaifera langsdorffii Desf. apresentando resultados similares aos estudos convencionais [2]. Com o estudo das variáveis envolvendo adsorção e eluição de Horseradish peroxidase (HRP) e peroxidase de soja (SBP) pela cromatografia concanavalina A-Agarose, foi indicado que a melhor condição para peroxidase de soja foi $\mathrm{pH}$ 5,0 e $1 \mathrm{~m} \mathrm{mol.L} \mathrm{L}^{-1} \mathrm{Ca}^{2+} / \mathrm{Mg}^{2+}$ na ausência de sal [3]. Para o monitoramento da atividade da enzima HRP verificaram as condições experimentais ótimas de $\mathrm{pH}$ 5,0 [4]. Assis et all [5] estudando enzima de acerola definiram condições de ensaio da enzima pectina metilesteraase (PME) de acerola, utilizando a metodologia de planejamento fatorial e a análise de superficie de resposta. Leite, et all [6], usando o planejamento fatorial definiram também as condições 
reacionais de catálise da PME de goiaba [6]. Os dados da literatura indicam a importancia e a eficiência do uso da técnica de planejamento fatorial para sistemas enzimáticos, o que poderia ser utilizado para estudos de extração e purificação de enzimas.

As peroxidases são enzimas classificadas como (doador: $\mathrm{H}_{2} \mathrm{O}_{2}$ oxidoredutase (EC 1.11.1.7) pertence a uma classe de proteínas que tem como função oxidar uma variedade de doadores de hidrogênio com consumo de peróxido de hidrogênio ou oxigênio molecular, assim como aceptor de elétrons em reações de oxidação [7]. Estas enzimas são encontradas em bactérias, fungos, plantas e vertebrados [8]. Peroxidase de soja (SBP) pertence à classe III da superfamília de peroxidase de plantas. Peroxidase de soja e a isoenzima HRP-C possuem grande similaridade em suas estruturas tridimensionais, com uma homologia seqüencial de 57\% [9]. Suas características em comum incluem ferriprotoporfirina IX como grupo prostético e mecanismo de catalise.

Casca de semente de soja, considerada um subproduto do processamento de soja, pode ser importante fonte de peroxidase. A padronização de uma metodologia extrativa acessível desta enzima pode levar a um maior valor agregado das cascas. Associado a isso, com os estudos cinéticos de caracterização enzimática e de aplicação analítica, pode-se constatar se a SBP apresenta especificidade catalítica análoga à peroxidase $\mathrm{HRP}$, o que poderá indicar potencial da SBP como fonte alternativa de peroxidase em substituição a HRP.

A considerável atenção biotecnológica pela peroxidase de soja (SBP) deve-se a sua alta estabilidade, e altas concentrações na casca do grão de soja [10]. Do ponto de vista tecnológico, as peroxidases em geral tem características interessantes que incluem alta estabilidade térmica, estabilidade ao pH, atuação em solventes orgânicos, e propriedades catalíticas bem definidas [11].

Para estudo de enzima deve-se estabelecer as condições de $\mathrm{pH}$, temperatura, natureza do tampão, entre outros, parâmetros estes que afetam a velocidade de reação. Peroxidase de diferentes fontes foram estudadas e suas condições de ensaio bem estabelecidas. Para isso os estudos são realizados variando cada parâmetro, na forma de tentativa e erro, após muitas curvas cinéticas, até se ter as condições definidas. [2; 12-16]. A busca por uma metodologia que auxilie numa definição precisa dos parâmetros cinéticos para o estudo de enzima, minimizando o numero de cinéticas e tempo, constitui o anseio de enzimologistas.
A proposta deste trabalho foi utilizar o planejamento fatorial e de superfície de resposta como ferramenta analítica para obter as condições ótimas do meio reacional da peroxidase de casca de soja (SBP), um subproduto do processamento industrial de grãos de soja brasileira.

\section{Materiais e Métodos}

Todos os ensaios espectrofotométricos foram realizados em espectrofotômetro UV/VIS HP 8452, diode array, acoplado a um microcomputador HP PC III.

Para obtenção do pó cetônico, estudos foram feitos com as cascas (tegumento) de soja fornecido pela UNISOJA, Unidade Auxiliar da Faculdade de Ciências Farmacêuticas / UNESP / Araraquara-SP, que produz leite de soja e yogurte de soja para Prefeituras Municipais de Araraquara e região. Neste caso a soja é proveniente de diferentes fornecedores, e não tem soja transgênica. Com as amostras das cascas de soja foi obtido o pó cetônico da seguinte maneira: uma certa quantidade de tegumeto de soja é congelada com nitrogênio líquido, triturada em almofariz até a obtenção de um pó, que em seguida deve ser lavado várias vezes com acetona a $-20^{\circ} \mathrm{C}$ até que a ultima lavagem saia sem coloração. $\mathrm{O}$ pó cetônico de tegumento de soja obtido foi mantido sob congelamento para posterior estudos de extração da enzima peroxidase (SBP).

Para otimização da extração (esquema 1) e condições de ensaio da SBP foram realizados testes exploratórios para obtenção do pó cetônico e da otimização das condições de extração, através de planejamento experimental, utilizando metodologia de superfície de resposta, compreendo-se o planejamento estatístico fatorial $2^{7}$, resultando 128 experimentos com três repetições. Os valores dos efeitos principais e de interação foram calculados empregando o programa estatístico MINITAB Statistical Software Release 13. Após determinar os parâmetros cinéticos qualitativamente, estabeleceuse o planejamento estatístico utilizando a metodologia de superfície resposta.

Para extração da enzima SBP, partindo-se gramas de cascas de soja adicionou-se tampão extrator na razão de 1:5 (grama de cascas de soja/mL de tampão), na ausência e na presença de $\mathrm{NaCl}$ nas concentrações $0,1 \mathrm{~mol} . \mathrm{L}^{-1} ; 0,03 \mathrm{~mol} . \mathrm{L}^{-1}$, e $0,05 \mathrm{~mol} . \mathrm{L}^{-1}$ de $\mathrm{NaCl}$, com o objetivo de obter SBP na forma de extrato bruto concentrado, conforme esquema 1. A 


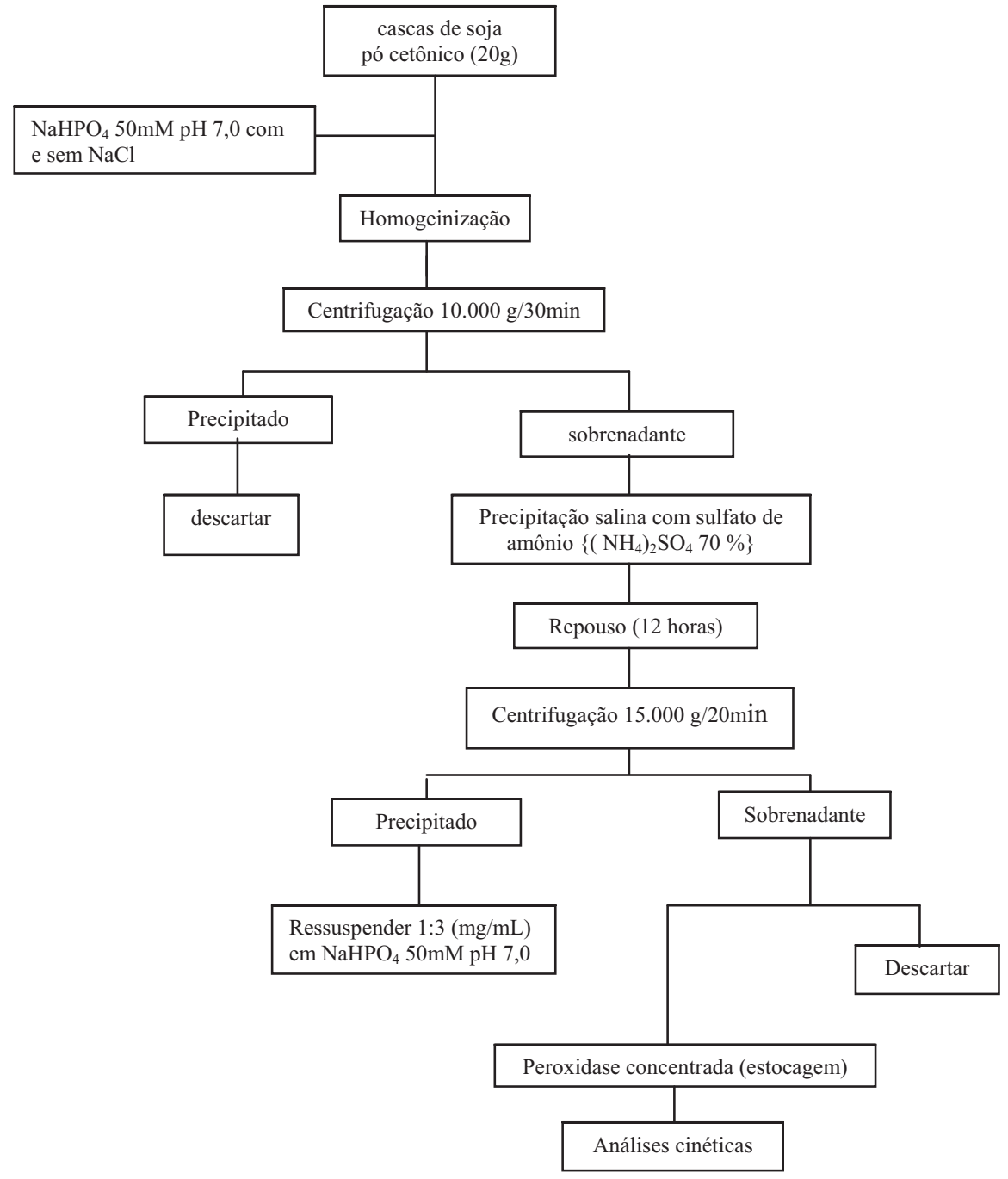

Esquema 1. Procedimento para extração de peroxidase

saturação com sal de sulfato de amônio foi feita segundo o nomograma de Dixon [12]. O precipitado obtido contendo a enzima foi ressuspenso com o tampão extrator na razão de 1:3 ( $\mathrm{g}$ de extrato/mL de tampão).

Para determinação da atividade de peroxidase, utilizou-se como meio de reação: $1218 \mu \mathrm{L}$ de tampão fosfato-citrato de sódio $50 \mathrm{mmol} \cdot \mathrm{L}^{-1} \mathrm{pH} 3,3 ; 300 \mu \mathrm{L}$ de

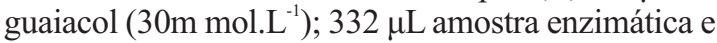
$150 \mu \mathrm{L} \mathrm{H}_{2} \mathrm{O}_{2}\left(4,2 \mathrm{mmol} . \mathrm{L}^{-1}\right)$. A reação foi seguida 470 $\mathrm{nm}$, durante 20 segundos, a $50^{\circ} \mathrm{C}$, no espectrofotômetro UV/VIS HP 8452, diode array, acoplado a um microcomputador HP - PC III, utilizando como substrato o guaiacol $[13,14,15]$.

Para determinação da Unidade de Atividade (U.A.) e da Atividade Específica (A.E.) definiu-se que uma unidade de atividade é a quantidade de enzima, que leva a uma variação de 0,010 de absorbância em um minuto, nas condições ótimas de ensaio. Com os dados de unidade de atividade e do conteúdo protéico total $(\mathrm{mg} / \mathrm{mL})$ das amostras, a atividade específica foi calculada segundo a seguinte fórmula:

$$
\text { A.E. }=\text { U.A. } / \text { MG proteina }
$$


Para a determinação das condições ótimas de atividade ( $\mathrm{pH}$ e temperatura) utilizou-se soluções tampão citrato-fosfato de sódio, com valores de $\mathrm{pH}$ entre 3,0 e 5,0; fosfato de sódio com valor de $\mathrm{pH} 7,0$ e Glicina- $\mathrm{NaOH}$ com valor de $\mathrm{pH} 9,0$.

\section{Resultados e Discussão}

A extração de SBP a partir do pó cetônico proporcionou uma maior atividade enzimática, ou seja, obtenção de maior quantidade de enzima ativa em relação à técnica de extração salina, partindo-se de cascas de soja congeladas.

A atividade da SBP em função da temperatura foi realizada entre $25^{\circ} \mathrm{Ce} 40^{\circ} \mathrm{C}$, partindo-se de dados da literatura onde indica que a temperatura ótima da SBPé $40^{\circ} \mathrm{C}(10)$.

Os estudos de otimização das condições de extração consistiram da verificação de alguns parâmetros na extração, tais como: concentração de $\mathrm{NaCl}$, efeito do $\mathrm{pH}$ da solução tampão, obtenção do pó cetônico e temperatura. Cada extração realizada nos estudos de otimização se obteve a partir de uma relação massa:volume de $1 \mathrm{~g}: 3 \mathrm{ml}$ de tampão fosfato de sódio $50 \mathrm{mmol} . \mathrm{L}^{-1} \mathrm{pH} 7,0$. Foi realizada também a extração clássica salina (sulfato de amônio 70\%). Nos estudos preliminares observou-se que nas concentrações de sulfato de amônio entre 85 e $90 \%$ de saturação, atividade da peroxidase no sobrenadante diminuiu cerca de $85 \%$. A Tabela 1 relaciona os dados de Atividade Específica (AE) da SBP com as seguintes diluições.

Realizaram-se estudos com concentrações de $\mathrm{NaCl}$ tais como: $0,1 \mathrm{~mol} . \mathrm{L}^{-1} ; 0,03$ mol.L $\mathrm{L}^{-1} ; 0,05 \mathrm{~mol} . \mathrm{L}^{-}$ ${ }^{1}$ de $\mathrm{NaCl}$ e sem $\mathrm{NaCl}$. A concentração adotada como ideal foi $0,1 \mathrm{~mol} . \mathrm{L}^{-1} \mathrm{de} \mathrm{NaCl}$.

Os experimentos cinéticos foram realizados, com os dados da velocidade inicial de reação, foram construídos os gráficos de superfície resposta (figura....), que forneceram as condições ótimas de: $\mathrm{pH}$, temperatura, peróxido de hidrogênio, tempo, guaiacol, quantidade da enzima (extrato bruto) e concentração de $\mathrm{NaCl}$.

No planejamento fatorial completo $2^{7}$ mostra os 7 fatores estudados com seus respectivos níveis +1 e -1 , resultando 128 experimentos o qual fornecerá as condições ótimas para $\mathrm{pH}$, temperatura, peróxido de hidrogênio, tempo, guaiacol, quantidade de enzima (extrato bruto) e concentração de $\mathrm{NaCl}$ (tabela 2).

Tabela 1. Relação entre AE da SBP, extrato com pó cetônico, e diluições da amostra.

\begin{tabular}{cccc}
\hline Diluições & Atividade Específica & Unidade deAtividade & Proteína $^{*}$ \\
\hline \multirow{2}{*}{ enzima: tampão } & $\mathrm{AE}^{\#}$ & $\mathrm{UA}^{*}$ & $(\mathrm{mg} / \mathrm{mL})$ \\
$1: 1$ & 12,3 & 10,45 & 0,85 \\
$1: 2$ & 66,8 & 12,02 & 0,18 \\
$1: 3$ & 110,9 & 8,87 & 0,08
\end{tabular}

Tabela 2. Planejamento Fatorial Completo.

\begin{tabular}{ccc}
\hline Fatores & Nível -1 & Nível+1 \\
\hline $\mathrm{pH}$ & 4 & 5 \\
tempo & 20 segundos & 40 segundos \\
temperatura & $30^{\circ} \mathrm{C}$ & $40^{\circ} \mathrm{C}$ \\
guaiacol & $100 \mu \mathrm{L}$ & $300 \mu \mathrm{L}$ \\
$\mathrm{NaCl}$ & $\mathrm{Sem}$ & $\mathrm{com}$ \\
Peróxido & $40 \mu \mathrm{L}$ & $100 \mu \mathrm{L}$ \\
Volume da amostra(Enzima) & $50 \mu \mathrm{L}$ & $200 \mu \mathrm{L}$ \\
\hline
\end{tabular}




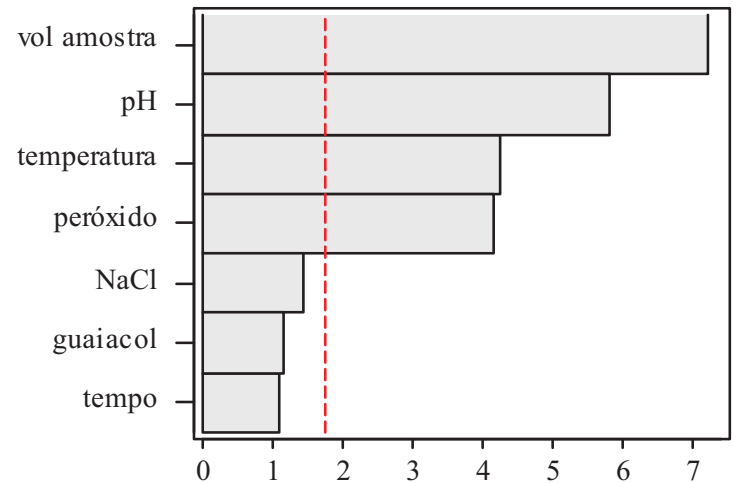

Figura 1. Gráfico de pareto dos efeitos investigados.
No gráfico de pareto (figura.1), pode-se observar os efeitos investigados. Aqueles que ultrapassaram a linha tracejada são significativos (enzima, pH, temperatura, e peróxido), enquanto que os fatores que não ultrapassaram a linha não são significativos ( $\mathrm{NaCl}$, guaiacol e tempo), portanto não influenciaram a atividade da enzima ao nível de significância de $95 \%$.

A Figura 2 apresenta os efeitos principais (similar ao gráfico de pareto) dos fatores acima apontados, na qual os segmentos de reta com maiores inclinações são mais significativos, enquanto que os segmentos de reta com menores inclinações são pouco significativos. Para cada fator também se pode observar no topo a indicação -1 e +1 (indicado os dois

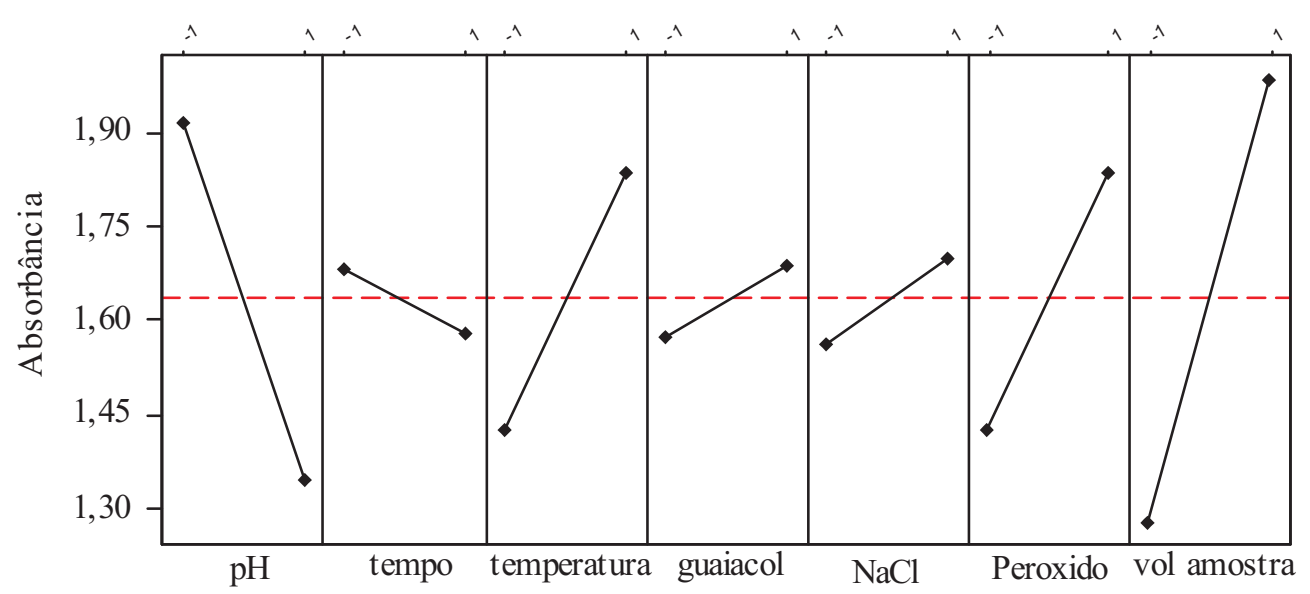

Figura 2. Efeitos principais para absorbância.

Tabela 3. Análise de variância para planejamento fatorial completo.

\begin{tabular}{lcccccc}
\hline Fatores & DF & Seq SS & Adj SS & Adj MS & F & p \\
\hline Blocos & 2 & 0,1906 & 0,1906 & 0,09532 & 1,66 & 0,225 \\
Efeitos principais & 7 & 7,2535 & 7,2535 & 1,03621 & 18,05 & 0.000 \\
Erro residual & 14 & 0,8037 & 0,8037 & 0,05741 & & \\
Total & 23 & 8,2478 & & & & \\
\hline
\end{tabular}

Limite de confiança $95 \%$.

DF - grau de liberdade.

SS - soma dos quadrados entre os grupos (fatores) e a soma dos quadrados com grupos (erro).

MS - média dos quadrados (dividindo a soma dos quadrados pelo grau de liberdade).

$\mathrm{F}-\mathrm{F}$ calculado dividindo o fator MS e pelo erro MS.

$\mathrm{p}$ - valor de $\mathrm{p}<0,05$. 
níveis investigados) para avaliar qual o melhor nível para cada fator. Assim tem-se:

- $\quad \mathrm{pH}=>$ melhor no nível $-1->\mathrm{pH} 4,0$

- temperatura $=>$ melhor no nível $+1->40^{\circ} \mathrm{C}$

- $\quad$ peróxido $=>$ melhor no nível $+1->100 \mu \mathrm{L}$

- $\quad$ volume amostra $\Rightarrow$ melhor no nível $+1->$ $200 \mu \mathrm{L}$

- Quanto aos menos significativos:

- tempo $=>$ melhor no nível $-1->20$ segundos

- $\quad$ guaiacol $=>$ melhor no nível $+1->300 \mu \mathrm{L}$

- $\quad \mathrm{NaCl}=>$ melhor no nível $+1->\operatorname{com~NaCl}(0,1$ mol. $L^{-1}$ )

A tabela 3 apresenta a análise de variância, onde são estudados os blocos e os efeitos principais, planejamento fatorial completo (ANOVA), mostrando o valor $p$ para cada efeito, sendo que valores de $p<0,05$ os efeitos principais são significantes.

Após a obtenção dos dados, elaborou-se o planejamento fatorial completo - segunda etapa para análise de superfície de resposta, ver Tabela 4.

Os dados da segunda etapa do planejamento demonstra que os 4 fatores investigados são significantes (Figura 4). Fica evidente que o volume da amostra (fator D) é o mais significante, seguido pelo $\mathrm{pH}$ (fator $\mathrm{A}$ ), enquanto que o temperatura $\mathrm{e}$ peróxido (fatores $\mathrm{B}$ e C) apesar de serem significantes são os de menor importância entre os

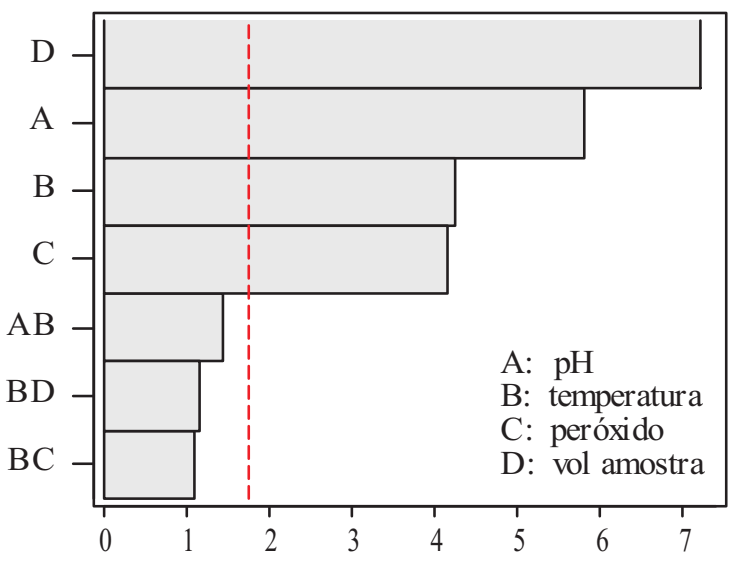

Figura 3. Gráfico de pareto dos efeitos investigados.

Tabela 4. Planejamento Experimental.

\begin{tabular}{ccc}
\hline Fatores & Nível -1 & Nível +1 \\
\hline $\mathrm{pH}$ & 3,5 & 4,5 \\
temperatura & $40^{\circ} \mathrm{C}$ & $50^{\circ} \mathrm{C}$ \\
Peróxido & $100 \mu \mathrm{L}$ & $150 \mu \mathrm{L}$ \\
Volume da amostra(Enzima) & $200 \mu \mathrm{L}$ & $350 \mu \mathrm{L}$ \\
\hline
\end{tabular}

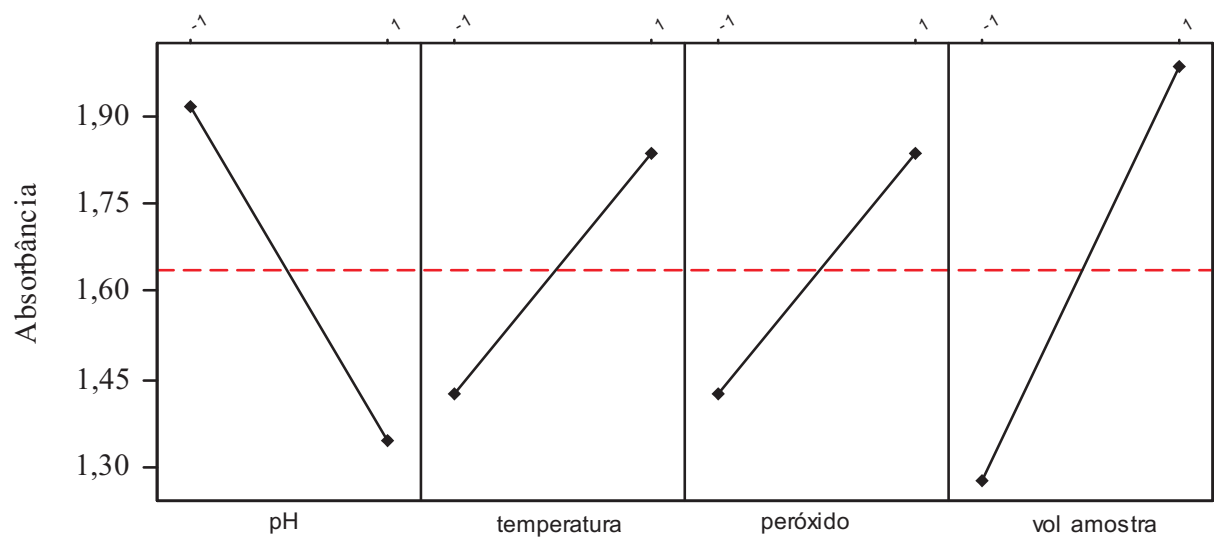

Figura 4. Efeitos principais para absorbância. 
quatro fatores considerados e comportam-se de forma similar (Figura 3).

$\mathrm{O}$ gráfico dos efeitos principais para absorbância (Figura 4) demonstra (pelas inclinações dos segmentos de reta) que todos os fatores são importantes. As melhores condições obtidas para maiores leituras de absorbância são quando o pH está em -1; enquanto que a temperatura, peróxido e volume da amostra estão em +1 .

O gráfico das interações entre os fatores investigados (Figura 5) as linhas tracejadas são para o nível +1 e as contínuas para o nível -1. Quando os dois segmentos são paralelos ou quase paralelos entre si a interação entre os fatores envolvidos não existe ou é de pequena importância. Quando os segmentos se cruzam, a interação entre os fatores envolvidos existe.

Na Tabela 5 de análise de variância (ANOVA) pode-se ver o valor $\mathrm{p}$ para cada efeito, com base no qual foi determinado se o efeito é significante ou não.

A análise de variância os efeitos principais estudados - $\mathrm{pH}$, temperatura, peróxido e volume da

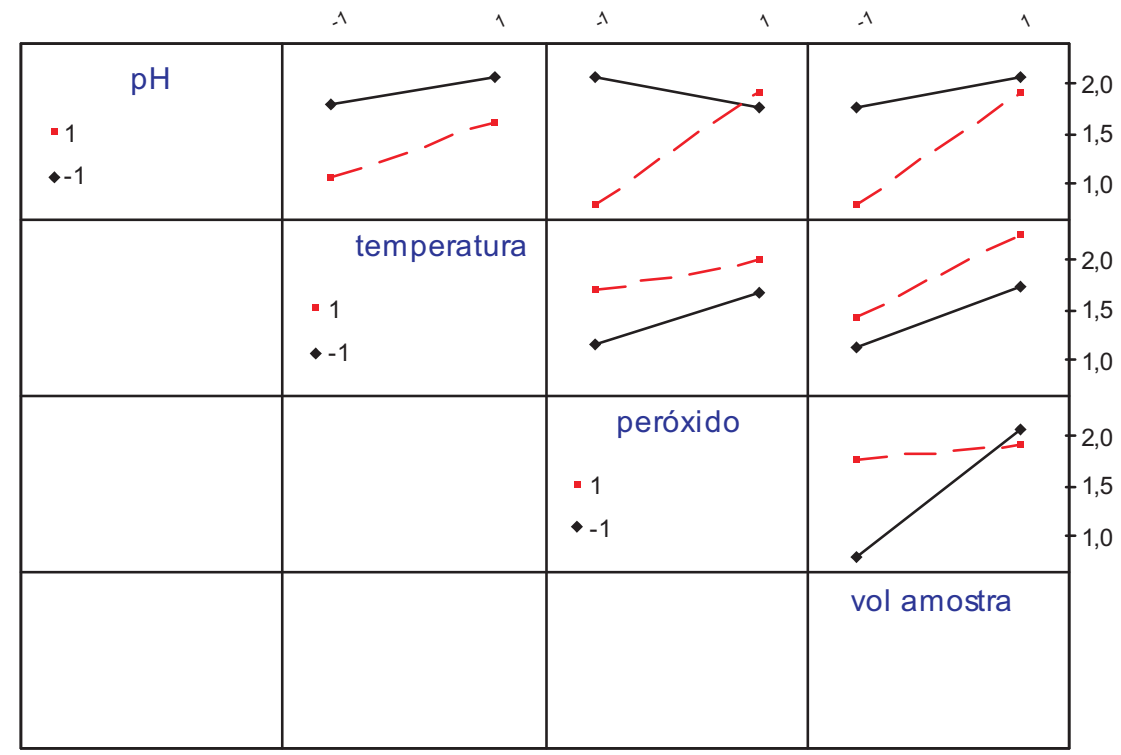

Figura 5. Interações entre os fatores investigados.

Tabela 5. Análise de variância para planejamento experimental (ANOVA).

\begin{tabular}{lcccccc}
\hline Fatores & DF & Seq SS & Adj SS & Adj MS & F & P \\
\hline Blocos & 2 & 0,1906 & 0,1906 & 0,09532 & 1,66 & 0,225 \\
Efeitos principais & 4 & 6,9905 & 6,9905 & 1,74763 & 30,44 & 0.000 \\
Interações & 3 & 0,2629 & 0,2629 & 0,08764 & 1,53 & 0,251 \\
Erro residual & 14 & 0,8037 & 0,8037 & 0,05741 & & \\
Total & 23 & 8,2478 & & & & \\
\hline
\end{tabular}

Limite de confiança $95 \%$.

DF - grau de liberdade.

SS - soma dos quadrados entre os grupos (fatores) e a soma dos quadrados com grupos (erro).

MS - média dos quadrados (dividindo a soma dos quadrados pelo grau de liberdade).

$\mathrm{F}-\mathrm{F}$ calculado dividindo o fator MS e pelo erro MS.

$\mathrm{P}-$ valor de $\mathrm{p}<0,05$. 
Tabela 6. Relação dos fatores investigados com os níveis experimentais ótimos.

\begin{tabular}{ccc}
\hline Fatores & Nível $\mathbf{- 1}$ & Nível+1 \\
\hline Ph & 3,5 & \\
Tempo & 20segundos & \\
Temperatura & & $50^{\circ} \mathrm{C}$ \\
Guaiacol & $300 \mu \mathrm{L}$ \\
NaCl & $\mathrm{Com}$ \\
Peróxido & $150 \mu \mathrm{L}$ \\
Volume da amostra(Enzima) & $350 \mu \mathrm{L}$ \\
\hline
\end{tabular}

Tabela 7. Relação dos fatores investigados com os níveis experimentais para superfície de resposta e gráfico de contorno.

\begin{tabular}{cc}
\hline Valor de $\mathrm{pH}$ & Volume da amostra $(\mu \mathrm{L})$ \\
\hline 3,0 & 279 \\
3,5 & 300 \\
2,8 & 350 \\
4,0 & 400 \\
4,2 & 421 \\
\hline
\end{tabular}

amostra - apresentada na tabela 5, mostra valores de $\mathrm{p}<0,05$ (nível de significância adotado), onde se pode ver que os efeitos principais são significantes. Enquanto que os blocos e as interações - pH / temperatura, temperatura / volume da amostra e temperatura / peróxido - apresentaram valor de $\mathrm{p}>$ 0,05 . Portanto, as interações não são significantes.

Em resumo pode-se dizer que a condição que apresenta atividade (absorbância) corresponde a que tem o pH em nível -1 e os demais fatores em nível +1 (Tabela 6).

Para finalizar, realizou-se outro estudo de superfície de resposta envolvendo novos ensaios

Tabela 8. Análise de variância para Contorno (ANOVA) .

\begin{tabular}{lcccccc}
\hline Fatores & DF & Seq SS & Adj SS & Adj MS & F & P \\
\hline Regressão & 5 & 1,4031 & 1,4031 & 0,28061 & 2,62 & 0,121 \\
Linear & 2 & 0,2038 & 0,4530 & 0,22652 & 2,11 & 0,191 \\
Quadrático & 2 & 1,0144 & 1,0144 & 0,50720 & 4,73 & 0,050 \\
Interação & 1 & 0,1849 & 0,1849 & 0,18490 & 1,73 & 0,230 \\
Erro Residual & 7 & 0,7502 & 0,7502 & 0,10717 & 1,71 & 0,302 \\
Lack-of-fit* & 3 & 0,4217 & 0,4217 & 0,14056 & & \\
Repetições & 4 & 0,3285 & 0,3285 & 0,08213 & & \\
Total & 12 & 2,1533 & & & & \\
\hline
\end{tabular}

Limite de confiança $95 \%$.

DF - grau de liberdade.

SS - soma dos quadrados entre os grupos (fatores) e a soma dos quadrados com grupos (erro).

MS - média dos quadrados (dividindo a soma dos quadrados pelo grau de liberdade).

$\mathrm{F}-\mathrm{F}$ calculado dividindo o fator MS e pelo erro MS.

$\mathrm{P}-$ valor de $\mathrm{p}<0,05$.

Lack-of-fit* este método identifica curvatura nos dados e interações entre os indicadores que podem afetar o ajuste do modelo. Sempre que os dados de subdivisão de p-valor é menor que o $\alpha$-nível: curvatura possíveis na variável x (valor de $\mathrm{p}$ $=0,006)$. 


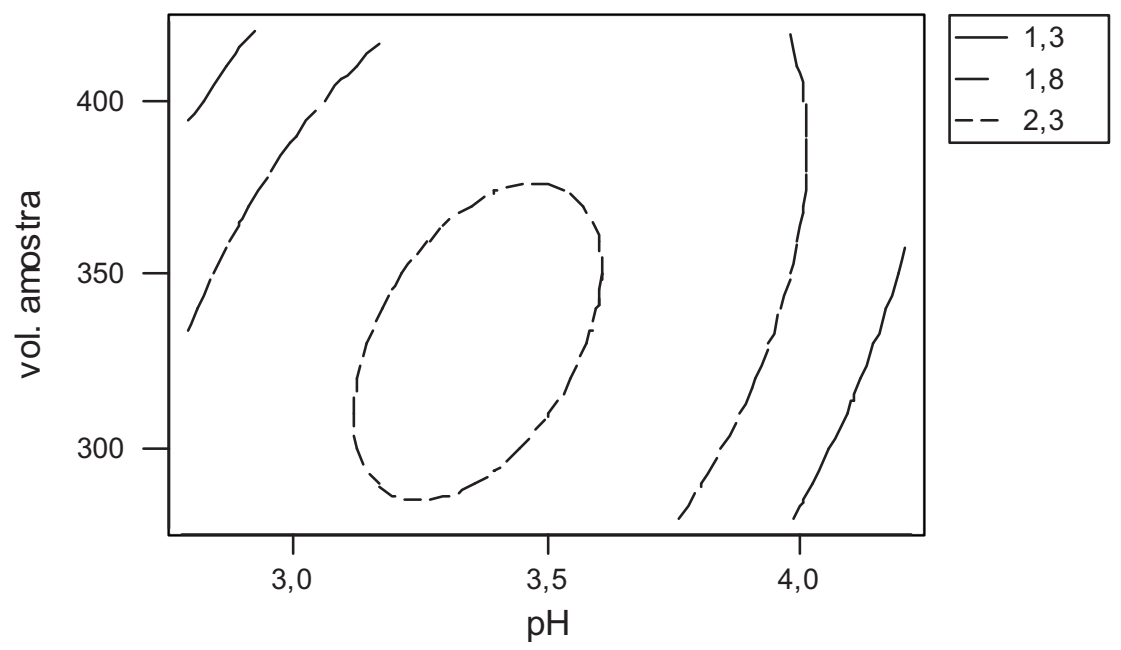

Figura 6. Gráficos de Contorno de Absorbância e de Superfície.

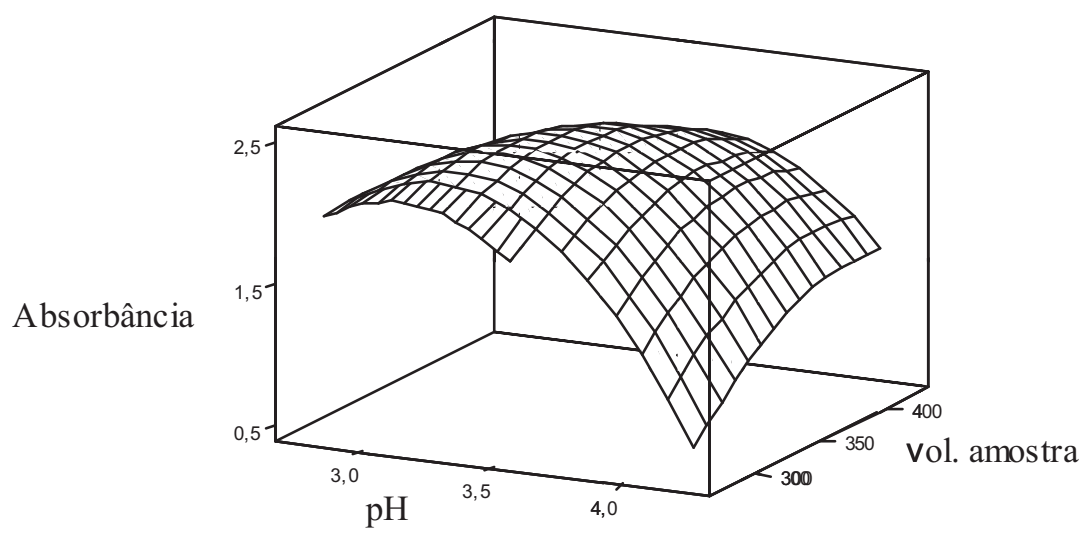

Equação da superfície de resposta:

Absorbância $=-13,22+8,40 \mathrm{pH}+0,0$ volume amostra $-1,75(\mathrm{pH})^{2}-0,0(\text { volume amostra })^{2}+0,01(\mathrm{pH}+$ volume amostra).

Figura 7. Gráfico de Superfície da Absorbância.

com os dois principais fatores: $\mathrm{pH}$ e volume de amostra como pode ser verificado na Tabela 7 . E, fezse a análise de variância que apresentou valor de $p$ $(0,05)$ no efeito quadrático, observando-se o valor significativo (Tabela 8).

Pelos gráficos de contorno (Figura 6) e de superfície de resposta (Figura 7) pode-se obter as melhores condições experimentais para os dois fatores analisados $(\mathrm{pH}$ e volume de amostra). A região de melhor reposta é observada de forma mais nítida pelo gráfico de contorno. Assim, as melhores condições estão dentro do elipsóide menor. Isto corresponde a pH entre 3,1 a 3,6 e volume de amostra de $290 \mu \mathrm{L}$ a $380 \mu \mathrm{L}$, mas as melhores condições estariam no centro do elipsóide com $\mathrm{pH}=3,3$ e volume de amostra de $330 \mu \mathrm{L}$ a $340 \mu \mathrm{L}$.

A Tabela 9 apresenta os valores de p na análise de variância de superfície de resposta para cada efeito 
Tabela 9. Análise de variância de superfície de resposta (ANOVA).

\begin{tabular}{lcccccc}
\hline Fatores & DF & Seq SS & Adj SS & Adj MS & F & P \\
\hline Regressão & 5 & 1,74509 & 1,74509 & 0,34902 & 4,85 & 0,031 \\
Linear & 2 & 0,20378 & 0,55860 & 0,27930 & 3,88 & 0,073 \\
Quadrático & 2 & 1,35641 & 1,35641 & 0,67820 & 9,42 & 0,010 \\
Interação & 1 & 0,18490 & 0,18490 & 0,18490 & 2,57 & 0,153 \\
Erro Residual & 7 & 0,50380 & 0,50380 & 0,07197 & & \\
Lack-of-fit* & 3 & 0,42168 & 0,42168 & 0,14056 & 6,85 & 0,047 \\
Repetições & 4 & 0,08212 & 0,08212 & 0,02053 & & \\
Total & 12 & 2,24889 & & & & \\
\hline
\end{tabular}

Limite de confiança $95 \%$.

DF - grau de liberdade.

SS - soma dos quadrados entre os grupos (fatores) e a soma dos quadrados com grupos (erro).

MS - média dos quadrados (dividindo a soma dos quadrados pelo grau de liberdade).

$\mathrm{F}-\mathrm{F}$ calculado dividindo o fator MS e pelo erro MS.

$\mathrm{P}-$ valor de $\mathrm{p}<0,05$.

Lack-of-fit* este método identifica curvatura nos dados e interações entre os indicadores que podem afetar o ajuste do modelo. Sempre que os dados de subdivisão de p-valor é menor que o $\alpha$-nível: curvatura possíveis na variável x (valor de $\mathrm{p}$ $=0,006)$.

estudado. Verificou-se que os efeitos como: Regressão, Quadrático e Lack-of-Fit apresentaram os valores de $\mathrm{p}<$ 0,05 . Esses valores $p$ apresentados foram significantes.

\section{Conclusões}

Pelos dados obtidos pode-se concluir que esse estudo também evidencia a grande utilidade de planejamento experimental, utilizando a metodologia de superfície resposta, para selecionar as melhores condições para peroxidase de soja (SBP). Assim, conclui-se que as melhores condições de ensaio com a SBP/Guaiacol/ $/ \mathrm{H}_{2} \mathrm{O}_{2}$, são:
- $\quad \mathrm{pH} 3,3$

- Volume da Amostra (Enzima) entre $330 \mu \mathrm{L}$; a $340 \mu \mathrm{L}$;

- $\quad$ Peróxido de hidrogênio $\left(4,2\right.$ mmol. $\left.\mathrm{L}^{-1}\right) 150 \mu \mathrm{L}$;

- Tempo 20 segundos;

- Temperatura $50^{\circ} \mathrm{C}$;

- $\quad$ Guaiacol $\left(30 \mathrm{mmol} . \mathrm{L}^{-1}\right) 300 \mu \mathrm{L} ; \mathrm{e}$

- $\quad 0,1$ mol. $\mathrm{L}^{-1} \mathrm{de} \mathrm{NaCl}$.

Após o estabelecimento dessas condições experimentais foi possível constatar que o rendimento obtido foi adequado para o estudo cinético enzimático de peroxidase de soja. 
Santos, M.C. , Tognolli, J.O., Oliveira, O.M.M.F. Chemometrics as analytical tool for definition of the conditions of assay of soybean peroxidase.

Abstract: Peroxidases enzymes are heme-proteins found in the different organisms livings creature, especially vegetal, present in important physiological paper/biochemist as protection against microorganisms. The soy, one of the most important products for the Brazilian agribusiness, presents in the rind of its seeds (byproduct) where has high activity of peroxidase, called soybean peroxidase, with potential of use in clinical analytical methods. The proposal of the work was to apply the factorial planning for optimization of the conditions extraction of this enzyme, definition of the conditions of kinetic-enzyme assay conditions ( $\mathrm{pH}$ and temperature), using methodology of reply surface. The data obtained: i) extraction in cetonico power, ii) reactional medium: $\mathrm{pH} 3,3$, volume of the sample contend enzyme $330 \mu \mathrm{L}-340 \mu \mathrm{L}$, hydrogen peroxide 4,2 mmol. $\mathrm{L}^{-1} 150 \mu \mathrm{L}$, time of reaction 20 seconds, temperature $50^{\circ} \mathrm{C}$, substrate guaiacol $30 \mathrm{mmol} . \mathrm{L}^{-1} 300 \mu \mathrm{L}$, and $0.1 \mathrm{~mol} . \mathrm{L}^{-1}$ of $\mathrm{NaCl}$. This chemometric methodology used to definition of the extraction conditions and parameters kinetic assay of soybean peroxidase was very efficient, compared the classical methodology of variations/repetitions (attempt and error).

keywords: soybean peroxidase; optimum temperature; optimum $\mathrm{pH}$; enzyme extraction; kinetic parameters

\section{Referências}

[1] Marco Flôres Ferrão, Claudia Wollmann Carvalho, Edson Irineu Müller, Celso Ulysses Davanzo. Ciênc. Tecnol. Aliment., Campinas, 24(3): 333-340, jul.-set. 2004.

[2] H. P. F. Maciel, C. M. C P. Gouvêa, G. M. Pastore, Ciências Tecnologia Alimentos. 27 (2007) 225.

[3] M. V. Miranda, M. L. Magri, A. A. Navarro del Canizo, O. Cascone, Process Biochemistry. 38 (2002) 543.

[4]C. V. Uliana, C. S. Riccardi, H. Yamanaka, Eclética Química. 33 (2008) 62.

[5] Assis et all

[6] Leite...2007,....

[7] R. A. Vierling, J. R.; Wilcox, Seed Science \& Technology. 24 (1996) 494.

[8] J. H. Dawson, Science. 240 (1988) 439.

[9] A. Henriksen, O. Mirza, C. Indiani, K. Teilum, G. Smulevich, K. G. Welinder, M. Gajhede, Protein Science.
10 (2001) 115 .

[10] M. A. Gijzen, The Plant Journal. 12 (1997) 998.

[11] L. Z. Munir, J. S. Dordick, Enzyme Microbiology Technology. 26 (2000) 341

[12] H. Wright, Nicell, A, Bioresource Technology. 70 (1999) 79.

[13] T. Suzuki, Y. Honda, Y. Mukasa, S-ju. Kim, Phytochemistry. 67 (2006) 224.

[14] C. L. Zanatta, M. F. Zotarelli, E. Clemente, Ciências Tecnologia Alimentos. 26 (2006) 708.

[15] M. Dixon, E.L. Webb, Academic Press. (1979) 47.

[16] K. K. Makinen, J. Tenovuo, Analytical Biochemistry. 126(1982) 108 .

[17] I. G. Gazarian, L. Lagrimini, Phytochemistry. 41 (1996) 1034.

[18] N. M. Khalil, Dissertação de Mestrado Faculdade de Ciências Farmacêuticas UNESP-Araraquara (2002).

[19] A. E. Zeraik, F. S. Souza, Fatibello-Filho, O, Química Nova. 31 (2008) 734. 
